\title{
Accumulation of steroidogenic acute regulatory protein mRNA, and decrease in the secretory and proliferative activity of rat adrenocortical cells in the presence of proteasome inhibitors
}

\author{
AGNIESKA ZIOLKOWSKA ${ }^{1}$, CINZIA TORTORELLA ${ }^{2}$, GASTONE G. NUSSDORFER $^{2}$, \\ MARCIN RUCINSKI ${ }^{1}$, MARIOLA MAJCHRZAK ${ }^{1}$ and LUDWIK K. MALENDOWICZ ${ }^{1}$ \\ ${ }^{1}$ Department of Histology and Embryology, Karol Marcinkowski University of Medical Sciences, PL-60781 Poznan, Poland; \\ ${ }^{2}$ Department of Human Anatomy and Physiology, School of Medicine, University of Padua, I-35121 Padua, Italy
}

Received November 7, 2005; Accepted December 23, 2005

\begin{abstract}
Sporadic findings indicate that proteolysis may affect steroid secretion in rat ovary granulosa cells. We examined the effects of the proteasome inhibitors MG115 and MG101 on the in vitro secretion and growth of rat adrenocortical cells. MG115 and/or MG101 decreased within 120 min the aldosterone and corticosterone secretion from freshly dispersed zona glomerulosa and zona fasciculata-reticularis (ZF/R) cells. After a 24-h incubation MG115 alone or with MG101 lowered corticosterone production and enhanced proliferation rate of cultured ZF/R cells, while MG101 was per se ineffective. Real-time polymerase chain reaction demonstrated that MG101 decreased steroidogenic acute regulatory protein (StAR) mRNA in cultured cells. MG115 was per se ineffective, but when added together with MG101 evoked a marked rise in StAR mRNA content. In light of the present findings, we conclude that i) protein breackdown by proteasomes is required for the maintenance of a normal secretory and proliferative activity of freshly dispersed or cultured rat adrenocortical cells; and ii) in long-term experiments, great caution must be taken in correlating StAR mRNA content and steroidogenic capacity.
\end{abstract}

\section{Introduction}

It is currently accepted that steroidogenic acute regulatory protein (StAR) plays a pivotal role in steroidogenesis, inasmuch as it regulates the rate-limiting step of this process (i.e. the translocation of cholesterol from the outer to the inner mitochondrial membrane) (reviewed in ref. 1). In steroidogenic

Correspondence to: Professor G.G. Nussdorfer, Department of Human Anatomy and Physiology, Section of Anatomy, University of Padova, Via Gabelli 65, I-35121 Padova, Italy

E-mail: gastone.nusdorfer@unipd.it

Key words: proteasome inhibitors, adrenocortical cells, steroid secretion, cell proliferation, steroidogenic acute regulatory protein, rat cells the $37 \mathrm{kDa}$ StAR preprotein is rapidly cleaved to the mature $30 \mathrm{kDa}$ protein $(2,3)$, and the estimated half-life of StAR preprotein trapped in the cytosol does not exceed $15 \mathrm{~min}$ $(3,4)$. Hence, StAR preprotein must be produced continuously if steroidogenesis is to be maintained.

Compelling evidence indicates that in most cultured mammalian cells under optimal nutritional conditions, 80-90\% of the protein breakdown occurs via the proteasome pathway and only $10-20 \%$ via the lysosomal system (reviewed in ref. 5). Convincing findings show that the bulk of short-lived regulatory proteins, including $\mathrm{StAR}$, is degraded by the ubiquitin-proteasome system $(3,6)$, and there is proof that treatment with proteasome inhibitors stabilizes regulatory proteins (5). In this connection, we recall that the proteasome inhibitor MG132 has been found to promote StAR protein accumulation and progesterone output in cultured rat preovulatory granulosa cells (6).

MG132 (Cbz-Leu-Leu-Leucin-al) is a peptide aldehyde which selectively inhibits the proteasome degradative pathway, and primarily chymotrypsin-like proteasome activity. In addition to MG132, other proteasome inhibitors are available: i) MG101 (N-Acetyl-Leu-Leu-Norleu-al), also named calpain inhibitor I; and ii) MG115 (N-Cbz-Leu-LeuNorvalin-al) (5). Therefore, it seemed worthwhile to investigate whether MG101 and MG115 influence StAR mRNA accumulation and function in rat adrenocortical cells.

\section{Materials and methods}

Animals and reagents. Adult female (130-140 g body weight) and 21-day-old male Wistar rats, bred in our laboratory facilities, were kept under a 14:10 h light-dark cycle (illumination onset at 6:00 a.m.) at $23^{\circ} \mathrm{C}$, and maintained on a standard diet and tap water ad libitum. Rats were decapitated and their adrenal glands were promptly removed and freed of adherent fat. The study protocol was approved by the local Ethics Committee for Animal Studies. MG101, MG115, ACTH, dimethyl sulfoxide (DMSO), bovine serum albumin (BSA) and all other chemicals were purchased from SigmaAldrich Corp. (St. Louis, MO). Dulbecco's modified minimum essential medium (DMEM)/nutrient mix and fetal calf serum (FCS) were provided by Gibco (Milan, Italy). 


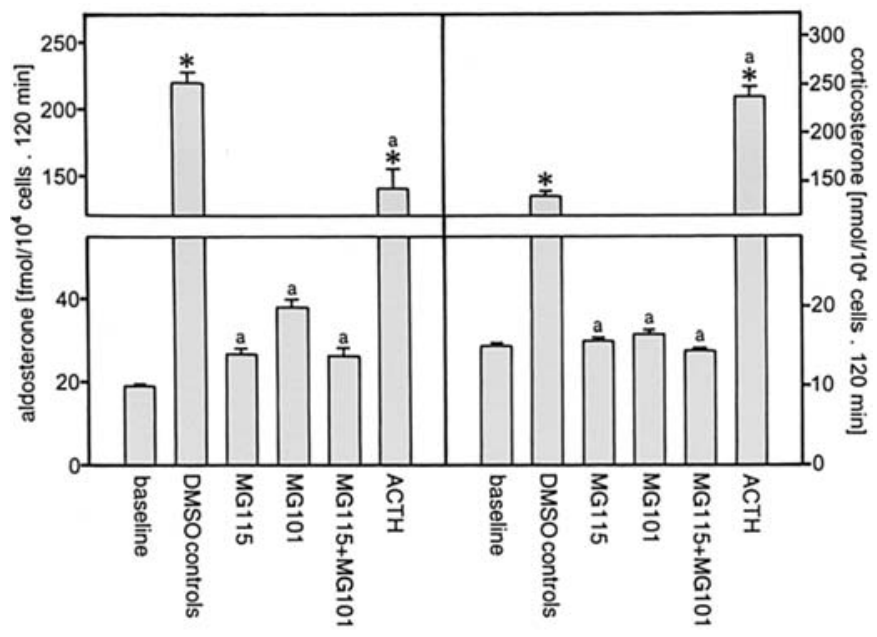

Figure 1. Effects of DMSO, protease inhibitors and ACTH on aldosterone and corticosterone secretion from freshly dispersed rat $\mathrm{ZG}$ and $\mathrm{ZF} / \mathrm{R}$ cells, respectively. Bars are means $\pm \operatorname{SEM}(n=6) .{ }^{*} \mathrm{p}<0.01$ from baseline; ${ }^{\mathrm{a}} \mathrm{p}<0.01$ from DMSO control group.

Dispersed adrenocortical cells. Adrenal glands of female rats were decapsulated to separate zona glomerulosa (ZG) from zona fasciculata-reticularis $(\mathrm{ZF} / \mathrm{R})$, and dispersed cells were obtained by sequential collagenase digestion and mechanical disaggregation (7). Dispersed cells obtained from 6-8 rats were pooled to obtain a single cell suspension, and 6 cell suspensions for each incubation experiment were employed. Cells were counted with the CASY cell counter and analyser systems (model TT; Schaerfe System, Reutlingen, Germany), and aliquots of each cell suspension $\left(10^{4}\right.$ cells $/ \mathrm{ml}$ in KrebsRinger bicarbonate buffer with $0.3 \%$ glucose and $0.2 \%$ BSA) were incubated with MG101 and/or MG115 (10-6 M) dissolved in $0.3 \%$ DMSO or DMSO alone. Other cell aliquots were incubated with ACTH $\left(10^{-8} \mathrm{M}\right)$ dissolved in $0.9 \% \mathrm{NaCl}$ or saline alone (control cells). The incubation was carried out in a shaking bath at $37^{\circ} \mathrm{C}$ for $120 \mathrm{~min}$, in an atmosphere of $95 \%$ air-5\% $\mathrm{CO}_{2}$. At the end of the experiment, the incubation tubes were centrifuged at $4^{\circ} \mathrm{C}$, and supernatants were stored at $-36^{\circ} \mathrm{C}$.

Adrenocortical cell culture. Dispersed adrenocortical cells obtained from young male rats were cultured as previously described (8). Briefly, cells were counted and seeded at a density of $10^{4}$ cells/well into 24- or 96-well cluster dishes, and cultured for $96 \mathrm{~h}$ at $37^{\circ} \mathrm{C}$ in DMEM (added with $1.125 \mathrm{~g} / \mathrm{l}$ sodium bicarbonate, $10 \%$ FCS, $100 \mathrm{U} / \mathrm{ml}$ penicillin and $100 \mu \mathrm{g} / \mathrm{ml}$ streptomycin), the medium being changed every $24 \mathrm{~h}$. At the day 4, cells were incubated for an additional $24 \mathrm{~h}$ with MG101, MG115 or ACTH, as described above. Culture medium was collected and stored at $-36^{\circ} \mathrm{C}$.

Reverse transcription (RT)-polymerase chain reaction (PCR). Cultured cells were harvested and frozen at $-80^{\circ} \mathrm{C}$. Total RNA was extracted as previously detailed (9), and contaminating DNA was eliminated by DNase-I treatment (RNase-free DNase set; Promega, Madison, WI). The amount of total RNA was determined by measuring optical density at $260 \mathrm{~nm}$ wavelength, and its purity estimated by $260-280 \mathrm{~nm}$ absorption

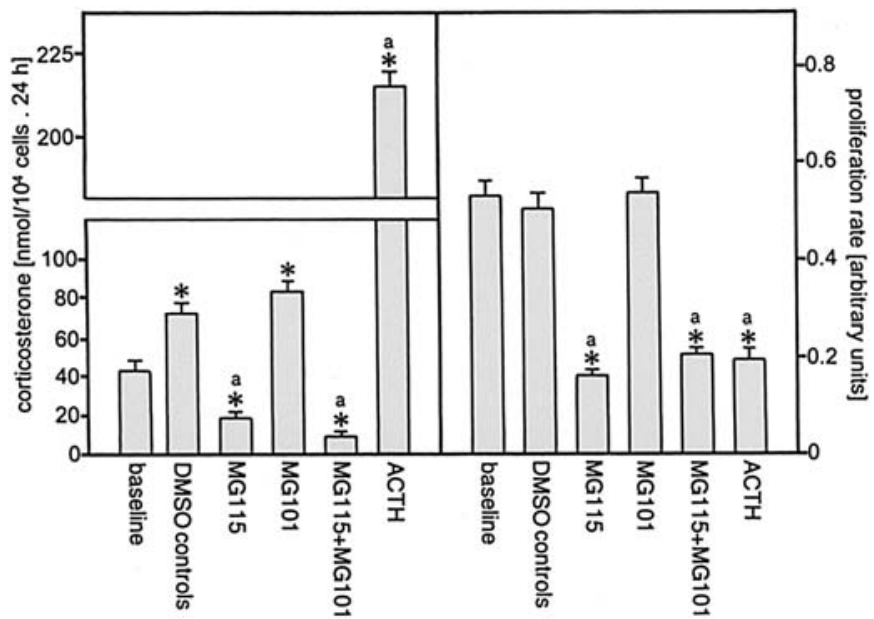

Figure 2. Effects of DMSO, protease inhibitors and ACTH on corticosterone secretion and proliferation rate of cultured rat $\mathrm{ZF} / \mathrm{R}$ cells. Bars are means \pm $\operatorname{SEM}(\mathrm{n}=8)$. ${ }^{*} \mathrm{p}<0.01$ from baseline; ${ }^{\mathrm{a}} \mathrm{p}<0.01$ from DMSO control group.

ratio, which was consistently $>1.8$. Equal amounts of total RNA $(0.5 \mu \mathrm{g})$ of each sample were reverse transcribed, and RT was carried out using AMV reverse transcriptase (Promega) with Oligo dT (PE Biosystems, Warrington, UK) as primers (9). Conventional PCR was performed as previously detailed $(8,10)$, and glyceraldehyde-3-phosphate dehydrogenase $(\mathrm{GAPDH})$ and $\beta$-actin were used as housekeeping reference genes. The primer sequence and the predicted size of the PCR products are indicated in the legend of Fig. 3. To determine the efficiency of target and reference reactions, standard curves for both StAR and GAPDH or ß-actin were prepared with products of conventional PCR separated on $2 \%$ agarose gel. Specific bands were extracted, using the DNA gel extraction kit (Millipore, Milan, Italy), and extracted cDNA was spectrofotometrically quantified. Standard curved were generated by 1:10 dilution of the isolated cDNA.

Semiquantitative real-time PCR. Real-time PCR was performed in a Roche LightCycler 2.0 with software version $4.0(11,12)$, using the primers indicated in the legend of Fig. 3. Briefly, reactions were carried out in $20 \mu 1$ of final volume solution, containing $4 \mu \mathrm{l}$ template cDNA, $0.5 \mu \mathrm{M}$ specific primers, $3.5 \mu \mathrm{M} \mathrm{MgCl}$ and $12.5 \mu \mathrm{l}$ LightCycler FastStart DNA Master SYBR-Green-I mix (Roche Molecular Biochemicals, Mannheim, Germany). The following PCR program was used: denaturation step $\left(95^{\circ} \mathrm{C}\right.$ for $\left.10 \mathrm{~min}\right)$, and 45 cycles of three-steps of amplification (denaturation, $95^{\circ} \mathrm{C}$ for $10 \mathrm{sec}$; annealing, $58^{\circ} \mathrm{C}$ for $5 \mathrm{sec}$; and extension, $72^{\circ} \mathrm{C}$ for $10 \mathrm{sec}$ ). Subsequently, melting curve $\left(60-90^{\circ} \mathrm{C}\right.$ with heating rate of $0.1^{\circ} \mathrm{C} / \mathrm{sec}$ ) was performed to check the specificy of amplification and the presence of byproducts. All samples were amplified in duplicate, and GAPDH and $\beta$-actin genes were used as reference to normalize data.

Hormone assay. Aldosterone and corticosterone concentrations in the incubation media were measured by RIA, as previously detailed (13). Intra- and inter-assay CVs were: aldosterone, 5 and $7 \%$; and corticosterone, 7 and $9 \%$, respectively. 


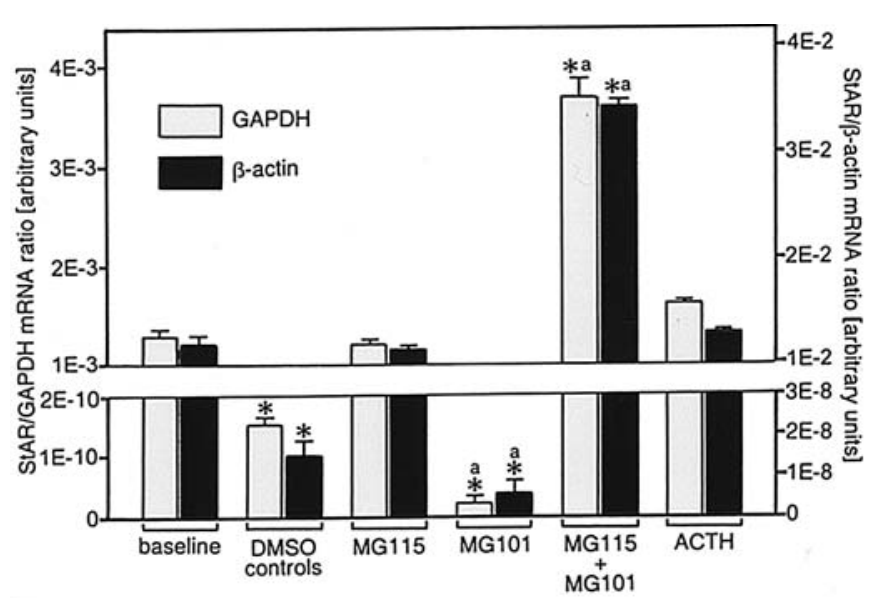

Figure 3. Effects of DMSO, protease inhibitors and ACTH on relative StAR mRNA expression (normalized to both GAPDH and $\beta$-actin genes) in cultured rat ZF/R cells. Primer sequences were as follows: i) StAR (NM_031558), sense, 5'-CCTGAGCAAAGCGGTGTCAT-3' and antisense, 5'-GCAAGTGGCTGGCGAACTCTA-3' (187 bp); ii) GAPDH (X02231), sense, 5'-AGAGACAGCCGCATCTTCTTC-3' and antisense, 5'-TTGAA CTTGCCGTGGTAGAG-3' (214 bp); and iii) B-actin (NM_031144), sense, 5'-AGCGCGTAACCCTCATAGAT-3' and antisense, 5'-TGAACACGGCA TTGTAACCA-3' (173 bp). Bars are means \pm SEM $(n=3)$. ${ }^{*} \mathrm{p}<0.01$ from baseline; ${ }^{\mathrm{a}} \mathrm{p}<0.01$ from DMSO control group.

Cell proliferation assay. Proliferation rate of cultured adrenocortical cells was assayed by the EZ4U non-radioactive cell proliferation and cytotoxic assay of Biomedica (Vienna, Austria), as detailed previously $(14,15)$. Briefly, cultures were incubated for the last $5 \mathrm{~h}$ with EZ4U and formazan production, which is linearly related to the cell number, was assayed by measuring absorbance at $490 \mathrm{~nm}$ wavelength in a microplate autoreader EL13 (Bio-Tek Instruments, Winooski, VT).

Statistics. Results were expressed as means \pm SEM of 6 separate experiments. The statistical comparison was done by ANOVA, followed by the multiple range test of Duncan.

\section{Results}

DMSO markedly enhanced aldosterone and corticosterone secretion from dispersed rat ZG and ZF/R cells. MG115 and/or MG101 decreased within 120 min mineralo- and glucocorticoid output with respect to the DMSO group, and ACTH enhanced it with respect to both control and DMSO groups (Fig. 1).

DMSO raised corticosterone secretion from cultured rat ZF/R cells, while MG115 alone or plus MG101 lowered it within $24 \mathrm{~h}$ with respect to both control and DMSO groups. MG101 was per se ineffective, and ACTH exerted a potent stimulating action (Fig. 2, left panel). DMSO did not affect proliferative activity of cultured rat ZF/R cells. MG115 alone or jointly with MG101 exerted a marked antiproliferogenic action, while MG101 alone was ineffective. As expected, ACTH inhibited proliferative activity of cultured cells (Fig. 2, right panel).

DMSO and MG101 decreased within $24 \mathrm{~h}$ the StAR mRNA in cultured rat ZF/R cells, while MG115 and ACTH were ineffective. However, MG101 plus MG115 markedly enhanced the StAR mRNA content (Fig. 3).

\section{Discussion}

DMSO, the widely used solvent in studies with proteasome inhibitors, is known to affect the function of several biological systems $(16,17)$. Accordingly, our findings indicate that $0.3 \%$ DMSO enhances steroid secretion from either dispersed or cultured rat adrenocortical cells, although lowering StAR mRNA content after $24 \mathrm{~h}$ exposure. These observations accord well with the results of previous investigations, where $5 \%$ DMSO was reported to abolish progesterone production from the mouse Leydig tumor cell line MA-10, and to block the synthesis of the StAR protein (18). Taken together, these findings stress that appropriate controls must be used in each study where DMSO is employed as a solvent.

Tajima et al (6) reported that within a 7-h exposure the proteasome inhibitor MG132 (10-30 $\mu \mathrm{M})$ promotes StAR protein accumulation and raises basal and hCG-stimulated progesterone output from cultured rat preovulatory granulosa cells. They concluded that StAR protein-degradation blockade by MG132 up-regulates progesterone synthesis. Our present results do not confirm this contention. In fact, i) in freshly dispersed rat adrenocortical cells, both MG101 and MG115 prevented the stimulating effect of DMSO on steroidhormone secretion; and ii) in cultured ZF/R cells MG115 alone or with MG101 lowered corticosterone production, although inducing, when administered together, a huge rise in StAR mRNA content.

Apart from the obvious differences between rat ovary granulosa and adrenocortical cells, it is difficult to explain the discrepancies between our present findings and those of Tajima et al (6). However, we recall that MG132 is primarily a chymotrypsin-like inhibitor, while MG101 and perhaps MG115 also block cathepsins and calpains $(5,19,20)$. Hence, it is possible to tentatively assume that our findings may, at least in part, ensue from the blockade of other than chymotrypsin-like proteolytic activities.

Another point which merits discussion is the fact that the MG115 plus MG101-induced inhibition of steroid-hormone production is coupled to a marked accumulation of StAR mRNA in cultured adrenocortical cells. StAR mRNA-content increase may not reflect up-regulation of StAR gene transcription, but only a decrease in its degradation rate. Moreover, it could be possible that the accumulated mRNA is not translated to StAR protein in the presence of proteasome proteolytic blockade. In this connection, it is to be taken into account that our estimations were carried out after a 24-h exposure to proteasome inhibitors. Evidence has been provided that ACTH, the main agonist of adrenocortical cell secretion, raises StAR gene transcription within 30-60 min, and that not all newly produced mRNA is translated to StAR-protein (reviewed in ref. 21). The ACTH-induced up-regulation of StAR gene expression is a rather short-lived effect, inasmuch as after $24 \mathrm{~h}$ of ACTH exposure in the absence of protease inhibitors non-significant changes in StAR mRNA content in adrenocortical cells can be observed.

In keeping with previous findings $(8,13,22)$, ACTH was found to inhibit in vitro growth of rat adrenocortical cells. The stimulation of specialized secretory functions of adrenocortical cells cultured in vitro is coupled with the inhibition of their proliferative activity (reviewed in ref. 23), 
MG115, but not MG101, was found to lower the proliferation rate of cultured adrenocortical cells, and the mechanism underlying such an effect is different from that of ACTH because MG115 impairs steroid-hormone synthesis. This observation agrees with earlier findings indicating that MG115 exerts a marked antiproliferogenic action acting at the G1/S and metaphase of the cell cycle (24).

Collectively, the present study allow us to conclude that in dispersed and cultured rat adrenocortical cells i) protein breackdown by the proteasome pathway is necessary for the maintenance of a normal steroidogenic and proliferative activity; and ii) caution must be taken in long-term experiments in correlating StAR mRNA content with the steroid-secreting capacity.

\section{References}

1. Stocco DM: StAR protein and the regulation of steroid hormone biosynthesis. Annu Rev Physiol 63: 193-213, 2001.

2. Stocco DM and Clark BJ: Regulation of the acute production of steroids in steroidogenic cells. Endocr Rev 17: 221-244, 1996.

3. Granot Z, Geiss-Friedlander R, Melamed-Book N, Eimerl S, Timberg R, Weiss AM, Hales KH, Hales DB, Stocco DM and Orly J: Proteolysis of normal and mutated steroidogenic acute regulatory proteins in the mitochondria: the fate of unwanted protein. Mol Endocrinol 17: 2461-2476, 2003.

4. Arakane P, Kallen CB, Watari H, Foster JA, Sepuri NB, Pain D, Stayrook SE, Lewis M, Gerton GL and Strauss JF III: The mechanism of action of steroidogenic acute regulatory protein (StAR). StAR acts on the outside of mitochondria to stimulate steroidogenesis. J Biol Chem 273: 16339-16345, 1998.

5. Lee DH and Goldberg AL: Proteasome inhibitors: valuable new tools for cell biologists. Trends Cell Biol 8: 397-403, 1998.

6. Tajima K, Babich S, Yoshida Y, Dantes A, Strauss JF III and Amsterdam A: The proteasome inhibitor MG132 promotes accumulation of the steroidogenic acute regulatory protein (StAR) and steroidogenesis. FEBS lett 490: 59-64, 2001.

7. Malendowicz LK, Nowak M, Gottardo L, Tortorella C, Majchrzak M and Nussdorfer GG: Cholecystokinin stimulates aldosterone secretion from dispersed rat zona glomerulosa cells, acting through cholecystokinin receptors 1 and 2 coupled with the adenylate cyclase-dependent cascade. Endocrinology 142: 4251-4255, 2001.

8. Ziolkowska A, Carraro G, Rebuffat P, Spinazzi R, Nussdorfer GG, Rucinski M and Malendowicz LK: Beacon[47-73] inhibits glucocorticoid secretion and growth of cultured rat and human adrenocortical cells. Int J Mol Med 14: 457-461, 2004.

9. Albertin G, Carraro G, Petrelli L, Guidolin D, Neri G and Nussdorfer GG: Endothelin-1 and adrenomedullin enhance the growth of human adrenocortical carcinoma-derived SW-13 cell line by stimulating proliferation and inhibiting apoptosis. Int $\mathrm{J}$ Mol Med 15: 469-474, 2005.
10. Andreis PG, Rossi GP, Bova S, Neri G, Nussdorfer GG and Mazzocchi G: Up-regulation of the adrenomedullin system mediates hypotension and hypoaldosteronism induced by simulated microgravity. Int J Mol Med 13: 551-555, 2004.

11. Albertin G, Carraro G, and Nussdorfer GG: Human adrnomedullin gene silencing by short interfering RNAs: a preliminary study. Int J Mol Med 15: 597-583, 2005.

12. Rucinski M, Andreis PG, Ziolkowska A, Nussdorfer GG and Malendowicz LK: Differential expression and function of beacon in the rat adrenal cortex and medulla. Int J Mol Med 16: $35-40,2005$.

13. Hochol A, Albertin G, Nussdorfer GG, Spinazzi R, Ziolkowska A, Rucinski M and Malendowicz LK: Effects of neuropeptides B and $\mathrm{W}$ on the secretion and growth of rat adrenocortical cells. Int J Mol Med 14: 843-848, 2004.

14. Malendowicz LK, Spinazzi R, Tortorella C, Nussdorfer GG, Ziolkowska A and Rucinski M: Effects of leptin and leptin fragments on corticosterone secretion and growth of cultured rat adrenocortical cells. Int J Mol Med 14: 873-878, 2004.

15. Malendowicz LK, Rebuffat P, Tortorella C, Nussdorfer GG, Ziolkowska A and Hochol A: Effects of met-enkephalin on cell proliferation in different models of adrenocortical-cell growth. Int J Mol Med 15: 841-845, 2005.

16. Wood DC and Wood J: Pharmacologic and biochemical considerations of dimethyl sulfoxide. Ann NY Acad Sci 243: 7-19, 1975.

17. Ali BH: Dimethyl sulfoxide: recent pharmacological and toxicological research. Vet Hum Toxicol 43: 228-231, 2001.

18. Stocco DM, King S and Clark BJ: Differential effects of dimethylsulfoxide on steroidogenesis in mouse MA-10 and rat R2C Leydig tumor cells. Endocrinology 136: 2993-2999, 1995.

19. Tsubuki S, Saito Y, Tomioka M, Ito H and Kawashima S: Differential inhibition of calpain and proteasome activities by aldehydes of di-leucine and tri-leucine. J Biochem (Tokyo) 119: 572-576, 1996.

20. Mellgren RL: Specificities of cell permeant peptidyl inhibitors for the proteinase activities of $\mathrm{mu}$-calpain and the $20 \mathrm{~S}$ proteasome. J Biol Chem 272: 29899-29903, 1997.

21. Lehoux JG, Mathieu A, Lavigne P and Fleury A: Adrenocorticotropin regulation of steroidogenic acute regulatory protein. Microsc Res Tech 61: 288-299, 2003.

22. Spinazzi R, Ziolkowska A, Neri G, Nowak M, Rebuffat P, Nussdorfer GG, Andreis PG and Malendowicz LK: Orexins modulate the growth of cultured rat adrenocortical cells, acting through type 1 and type 2 receptors coupled to the MAPK p42/ p44- and p38-dependent cascades. Int J Mol Med 15: 847-852, 2005.

23. Nussdorfer GG: Cytophysiology of the adrenal cortex. Int Rev Cytol 98: 1-405, 1986.

24. Machiels BM, Henfling ME, Gerards WL, Broers JL, Bloemendal H, Ramaekers FC and Schutte B: Detailed analysis of cell cycle kinetics upon proteasome inhibition. Cytometry 28: 243-252, 1997. 